\title{
A LANGUAGE APPRAISAL OF HOTEL WEB PAGES IN INDONESIA FIVE STARRED HOTEL: INTERPERSONAL MEANING
}

\author{
Suyik Binarkaheni \\ Linguistics Program, Faculty of Humanities, University of Jember, Indonesia \\ sbinarkaheni@gmail.com
}

\begin{abstract}
This article aims to examine the interpersonal meaning of hotel web pages using the Appraisal framework in the view of assessing the frequent occurrence of the appraisal subsystem in the text. The employment of attitudinal, graduation and engagement of text construe the alignment. They explain how the hotel introductory text construction does align the reader. Martin \& White (2005) argued that appreciation reaction framework determines interpersonal significancies. The emotive prosody of this appreciation reaction is "it grabs me", decorative, and then "I want it" (Martin \& White, 57:2005). The dominant result of appreciation resources of reaction is shown in this research than other appreciation resources. We can replace the word "it" with the prosody of appreciation. As a result, the appreciation reaction of quality appears dominantly (44\%). It means that the hotel talked much about the things: facilities and services. Finally, the interpersonal meaning of the hotel Webpages is 'I am the most / I am the best'. It implies that the hotel is the best in quality and services in order to attract the reader. It proves that the web pages authentically in constructing the text in order to persuade the potential customer to purchase the hotel product.
\end{abstract}

Keywords: Hotel Webpages; Appraisal; Interpersonal Meaning

DOI: 10.15642/NOBEL.2019.10.1.52-70

Language enables human to express thoughts, ideas, and feeling. They share it for communication. Effective communication will be obtained when the speaker/writer and the listener/reader in the encoding and decoding process have the same sense and interpretation. However, people have different personal own life, such as the way they have personally experienced things and personal emotional responses. It leads the differences ways of communication to be encoded, transmitted and decoded. The function of language is purposeful, that it is to engage the participant in communication. However, some people find difficulty in saying what they mean. It is because of the way they present their ideas is really hard to evaluate. Evaluation defines as a means to ascertain the value of a certain idea in order to make ongoing communication. The values concern about the terms or the lexis that is showed through a judgment of people behavior or thing and showing emotion. It is used to show the speaker/writer attitude, stance, point of view and feeling about the entities or proposition of their opinion. It requires language evaluation of something positive or negative, good or bad, approval or critical entities, proposition and process. Meanwhile, the intended 
evaluation of written text is to identify the writer's opinion/belief/idea through the information in supporting reason and the evidence provided in the text. Houston and Thompson (2001) identified the functions of evaluation discourse in three performances: (1) It expressed the writer's values opinion, means that the value of his opinions was representing his community, (2) It constructed the relation of writer and reader, and (3) It told the point of the discourse.

Martin and White (2005) promoted an Appraisal theory. It examines the variety of speaker/ writer's language used in delivering an opinion, in the term of lexical choice and phenomenon. This theory is developed within the framework of Interpersonal metafunction in Systemic Functional Linguistics (SFL). Halliday (1994) defines SFL as an approach to the study of the meaning-making language in use in the textual processes in social life. In SFL, the meaning of language can be seen to occur on three different levels simultaneously. One of them is an interpersonal metafunction. It deals with the what relational and positional function of language being used by the participant of the context they are involved in. It based on the role of negotiation that plays by participant's utterance involve in the process of communication. The function of language is asking or giving information, services and goods, on the other hand, negotiation has language (speech) roles in human communication: giving some strangers directions, asking someone to close the door (service), expressing opinions. While Appraisal analysis concerns with the classification of evaluative language lexis. The term of lexis is not intended as an appraisal as a mechanical action but it is more than its ability to construct speaker identity, to align people in ongoing negotiations of communal life. From the participant's utterance performance, appraisal enables us to explain and describe the feeling and attitude, thus it describes the position and relationship of the participant in the context.

This research examines the interpersonal meaning of the language (evaluation) in the introductory of Bali and Yogya hotel homepage text. The resource of the interpersonal meaning will be explored lexically by the appraisal framework. The appraisal framework classifies the hotel homepage lexis (writer) into positive feeling or negative emotion (affective), giving aesthetic assessment toward things (the hotel product) and identify the judgment of writer's behavior (character) in promoting the hotel product. The three interpersonal values above are included in the first subsystem of attitude. The second subsystem is graduation. It assesses the enhancement of the quantity and intensity of lexical features on the hotel homepage in promoting their product. The last subsystem is engagement, which assesses the degree of lexical features commitment in promoting the hotel product. All 
those Appraisal tools are concerned with the assessment of the writers to align or dis-align themselves with the customer and how the writers construct their text for the intended customer.

The interpersonal meaning is identified by exploring the homepages texts through the writer/speaker's evaluative language in promoting online hotel booking. It is important for linguistics genre analysis for many reasons. First, it contributes to ESP's learner to know the vocabulary (lexis and phrase) appearance in the context of advertising the hotel online. Second, it gives deeper meaning in information of the terminology or lexis in text, dealing with question of the language function represented by text (Do the text do what is set out to do?) and the presentation of the interesting values written in the text (Do the writer present the reader with something interesting and engaging?). The problems arouse whenever the hotel engages the reader through the homepage of hotel implied in the using of an evaluative language in the text in order to convince the reader (how can the appraisal analysis describe the entities and proportion of homepage text in positively in the product?). In a brief, it continues to the next question, how can a text-align or disalign the reader?. The attitudinal meaning of hotel to construct the interpersonal relationship between the reader will answer the last question.

\section{REVIEW OF LITERATURE}

The appraisal system is a system that describes the choices of evaluative lexis ( the area of meaning potential) that is expressed in speaker's and writer's opinion in performing speech function. Martin and White in Hunston (2011:24) called this area of meaning potential by appraisal. The mechanism of evaluative meaning within appraisal will construe the revealing speaker's feeling and opinion by approving and disapproving, enthusing and abhorring, applauding and criticizing and they posit their reader to have the same feeling through the construction of their text. It is concerned with the mechanism of linguistic, how speaker/writer sharing emotion, taste and normative assessment to build an identity to align or dis-align their reader (Martin and White, 2005:2). Here, when the speaker/writer performs the speech function and does a role of exchange, the evaluative lexis will operate the degrees of greater and lesser the involvement of speaker which those they intended. Martin and White (2005:56) have a classification of evaluative lexis that it is used to manage the social intimacy (involvement) of the speaker and negotiate. Social intimacy reflected the identity, social role and human relation in interpersonal meaning. The appraisal system is divided into 3 domains, they are attitude, graduation, and engagement (Martin and White, 2005:34) 


\section{Attitude}

The terminology of attitude within appraisal analysis in which it is positioned the addressee to adopt the positive or negative feelings of phenomena, people or entities. There are three subtypes in assessing the attitudinal meaning, they are affect, appreciation and judgment. They will be explained in detail:

\section{Affect}

The resource that it is used in assessing positive or negative emotional reaction. There are two kinds of affective types based on the voice of the personae. Martin and White (2005: 46) divided three resonancies of affect resources. They are: expressing quality, process, and comment.

expressing quality

- describing participant

- attributed to participant

- manner of process

Expressing process

- Affective mental

- Affective behavioral

Expressing comment

- desiderative

\section{Appreciation}

The resource that is used in assessing positive or negative entities. They could be things, person, and phenomena. It is divided into 3 resources. They are:

\section{Reaction (related to affection/emotive)}

- Impact. It triggers the reader's feeling to things related to emotion(Did it grab me?).

Example: you're sure to have an unforgettable vacation in Bali

- Quality. It gives a quality of things (Did I like it?).

Example: ....with all the benefits of a resort.

Composition (related to our perception of view of order)

- Balance. It relates to the harmony between hotel product and services (Did it hangs together?)

Example: Our spacious hotel rooms and suites all feature an outdoor balcony with spectacular views of the lagoon or lush gardens, comfortable bedding and elegant marble bathrooms. 
- Complexity (is it hard to follow?)

Example: Nestled deep in heart of Ubud rain forest preserve, surrounded with the historical Petanu River and stunning jungle landscape, the Kayon has a healing atmosphere and romantic ambiance.

Valuation (related to a status and a social significancee; Was it worthwhile?)

Example: Well known for its friendly staff and the warm Balinese hospitality.

\section{Judgment}

The resource that is used in assessing positive or negative behavior according to various normative principle.

To social esteem

- to normality principle (how unusual someone is)

Example: our legendary staff.

- to tenacity (how independent someone is)

Example: Through careful consideration of the effects that operating systems, materials, and purchasing policies have on the environment.

- to capacity (how someone is dependable)

Example: Our staffs are experienced hoteliers in the industry

To social sanction

- To veracity (how truthful some is)

Example: he was a truthful waiter

- to prosperity (how ethical some is)

Example: she is a caring housekeeper

\section{Graduation}

It is to examine attitudinal meaning. It deals with the greater or lesser of positivity and negativity of affect, appreciation and judgment. They are focus and force. Force is the grammar of appraisal by which gradable resource are scaled by size, vigor, extent, and proximity (Martin and White, 2005). Force operates intensification and quantification of the gradable resource. Intensification is divided into two kinds of lexical classes, they are isolating and infusing. The differences of both of them are on the way they perform the scale of up/down. The isolated resource force is concerned with the scale up/down phenomena in which the function performance of intensity is construed by some other lexis in semantic function. The examples of the isolated force resource are: less miserable, least miserable, more miserable. Meanwhile, the infused resource force is concerned with the scale up/down 
phenomena in which the function performance of intensity is construed by single lexis. The examples of the infused force resource are: happy, joyous, possible, probably, certain. Besides, quantification concerned with the scale of number, such as size, weight, strength \& amount, time $\&$ space (how widely/how long distributed) and proximity of time $\&$ space (how time/often, how close) (Martin and White, 2005). Focus is the grammar of appraisal by which proposition is scaled to the degree to which they match some phenomena cores of semantic view (sharpen) and or vice versa (softened). The distinction is under the sharpen focus the meaning of real and true. The intended is in order to maximize the investment of speaker/writer in the value position (negative/positive) being advance and align strongly the reader/listener to come into that value position being advanced (Martin and White, 2005). The examples are:

- Sharpen 1. A real father (biology father)

2. A true friend (really friendship)

- Soften 1. They play sort of jazz (they dont play a real jazz)

2. He is rather crazy (he is not a crazy man)

Martin and White (2005:138)

\section{Engagement}

It is to identify the hotel homepage texts whether they are monoglossic or heteroglossic. If there is no reference to other voices in the context it will be monogloss utterances. On another side, if it invokes or allows dialogistic phenomenon there will be heterogloss utterances. Engagement could be analyzed from the monoglossic utterance, e.g., the bank have been greedy and heteroglossic utterance, e.g., there can be no denying the banks have been greedy (Martin and White, 2005: 100).

\section{METHODS}

This research aimed to examine the interpersonal meaning of the hotel homepage texts by applying Martin and White appraisal theory (2005). It started by (1) classifying the evaluative lexis, phrase and clause of the text, then (2) assessing the evaluative language using three parameters of appraisal, they are (a) attitude, that it consists of affective, appreciation and judgment, (b) graduation that it consists of focus \& force and (c) engagement that it consists of monogloss and heterogloss. The data are classified and presented in the form of tables. After conducting the two steps, the third step is analyzing the element of appraisal to figure out how they contribute to the conveyance of attitudinal position in the text. 


\section{RESULTS AND DISCUSSIONS}

\section{Results of the study}

Because the interpersonal meaning is concerned with the text constructions by sharing feelings and value via language, so it is necessary to show the total amount of words and identification words by counting and classifying the parts of speech. Based on the word analysis of this research, the words were categorized into a noun, adjective, adverb, conjunction, determiner, number, preposition, pronoun, and verb. The result could be seen in Table 4.1

Table 4.1 Part of Speech and Frequency of Words Hotel Home Pages in Bali and Yogyakarta

\begin{tabular}{llccc}
\hline No & & Hotel & Percentages of word & Word \\
\hline 1 & Noun & $78 \%$ & 317 \\
2 & Adjective & $26 \%$ & 203 \\
3 & Verb & $24 \%$ & 192 \\
4 & Preposition & $22 \%$ & 176 \\
5 & Number & $3 \%$ & 17 \\
6 & Determiner & $14 \%$ & 186 \\
7 & Adverb & $7 \%$ & 54 \\
8 & Pronoun & $6 \%$ & 48 \\
9 & Conjunction & $12 \%$ & 102 \\
\hline & & & 1.606 \\
\hline
\end{tabular}

Bhatia (1997) in Yi (2013) argued that adjectives are the basis of selling power in most promotional text and advertising genres. It is because the adjectives are used to describe and explain the product in detailed. And it has impacted positively in evaluating the product. Furthermore, evaluating hotel positively is crucial because it could align potential readers' attitude toward the hotel positively. Based on table 4.1, the frequency of adjectives come to the second dominantly in the text, which reaches $26 \%$. It implies that the hotels evaluate the products (noun) positively. So, the text construction of hotel homepages aligns the reader.

How the ten hotel homepages employ a particular evaluative strategy, the result of attitudinal appraisal classification based on the attitudinal appraisal theory is described in table 4.2. The attitude is concerned with the hotel's feeling, emotional reactions, judgment of behavior and evaluating the things. The clauses were classified into the three parameters of attitudinal appraisal. The appreciation was concerned with the hotel's evaluative language in describing things in details to the reader. Things mean the facilities and services. The affective was concerned with the hotel's evaluative language which triggers the positive emotion of the reader. The judgment is concerned with staff behavior in giving services. All 
the evaluative language means to do promotion in order to persuade the reader to stay in that hotel.

Table 4.2 The Detailed Calculation of Attitudinal Tools Hotel Homepages in Bali and Yogyakarta

\begin{tabular}{clccc}
\hline \multirow{2}{*}{ No } & \multirow{2}{*}{ Hotel Bali } & \multicolumn{3}{c}{ Attitudinal Term } \\
& & Appreciation & Affective & Judgment \\
\hline 1 & Hotel Ardhana Bali & 18 & 0 & 0 \\
2 & FuramaXclusive Villas \& Spa Ubud & 25 & 2 & 0 \\
3 & Swiss-Bel resort Watu imbar & 46 & 1 & 0 \\
4 & Fairmont Sanur Beach Bali & 18 & 1 & 0 \\
5 & Inaya Putri Bali & 14 & 0 & 0 \\
6 & Hyatt Regency & 19 & 0 & 2 \\
7 & Sheraton Mustika Yogyakarta Resort \& Spa & 12 & 1 & 1 \\
8 & The Meliá Purosani & 27 & 1 & 0 \\
9 & Grand Aston Yogyakarta & 23 & 1 & 0 \\
10 & Yogyakarta Marriot Hotel & 27 & 2 & 0 \\
\hline & \multicolumn{1}{c}{ Total } & $\mathbf{2 2 9}$ & $\mathbf{9}$ & $\mathbf{3}$ \\
\hline
\end{tabular}

Figure 4.2 is the pattern summarizes the attitude of the ten hotel homepages. The most attitudinal frequency comes from the appreciation of $95 \%$ among the two parameters, affective (4\%) and judgment (1\%). It implies that the text construction of 10 (ten) hotel homepages much emphasis on presenting the value of things. It means that the hotel homepages focus on promoting the hotel product: facilities and services

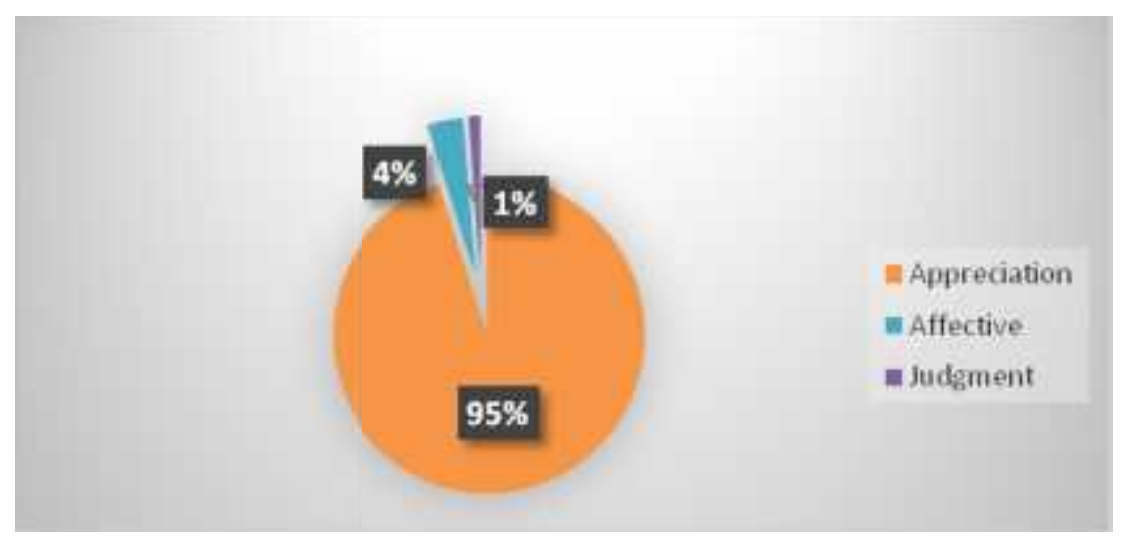

Figure 4.2 Pattern of Attitude of Hotel Homepages in Bali and Yogyakarta

\section{Discussion}

The interpretation appraisal analysis is used to evaluate language used and examine how language construct the interpersonal relationship in different communication purposes (Martin, 2005). The system of appraisal analysis explains the three domains in meaningmaking. They are attitude, graduation and engagement. There are $95 \%$ of appreciation, $1 \%$ for 
judgment and $4 \%$ for affection. All the results represent the attitudinal meaning of the text. The attitudinal construes the feeling of the writer. The feeling implied in the homepages text construction is used to align or disalign the reader. Graduation concerned with how the hotel homepages text amplified themselves to align the reader. While engagement deal with the engagement language to align the reader positively or negatively.

\section{Appreciation}

How the hotel homepages texts-align the reader positively in order to buy the hotel product? Figure 4.2 shows that appreciation reaction of quality (44\%) frequent dominantly. Appreciation evaluates things (entities) and phenomena. The appreciation reaction of quality is concerned with evaluating things. It implies that the text construction of 10 (ten) hotel homepages much focus on presenting the hotel products in detail, so it triggers the reader to have the feeling of "Did I like it " ?.

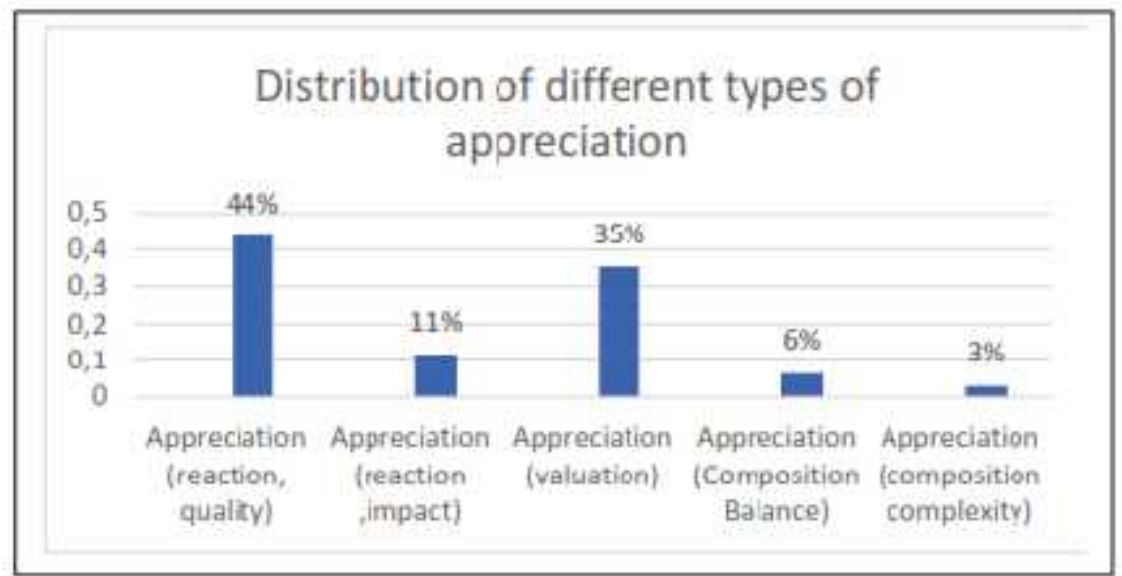

Figure 4.2 Pattern of Appreciation of Hotel Homepages in Bali and Yogyakarta Positive Reaction of Quality

The term reaction tends to mean construing writer's opinion about quality (thing or phenomena). The words are found in the following :

(29) Contemporary tropical living can be experienced across the 120 luxurious suites and villas, where each unit offers expansive space, peace and round-the-clock on-call butler service.

(18) Our guestrooms are inspired by tropical living in south-east Bali, designed in a postmodern, contemporary style with soothing earth tones and wood interiors.

(19) All rooms feature complimentary wireless Internet access, a private safe, a large flatscreen television and a day bed.

(70) Business travelers value our free Wi-Fi and ample work desks. 
(52) All our rooms are designed to offer comfort and grandeur with gorgeous views of the lush tropical garden or city. The hotel so features an outstanding range of cuisine, our restaurants and bars offer delightful dining options that will satiate any appetite.

(35) Throughout, the resort's seven themed buildings are resound with the spirit of Bali and

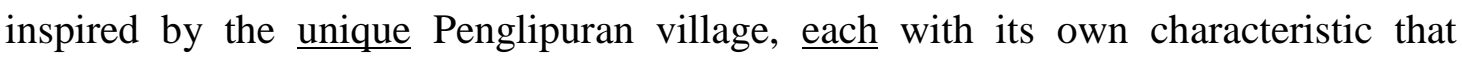
distinguished by impressive Indonesian stone work

(69) Every room features marble bathrooms, mini-refrigerators, flat-screen TVs and 24-hour room service.

(45) Sheraton Mustika Yogyakarta Resort and SPA is suitable for a family vacation or

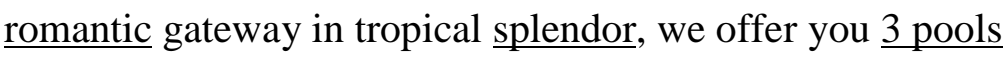

The examples above show the detail description of the accommodation with the result of the positive reaction of quality. It is used to evaluate the quality of facilities and the environment of the hotel room and villa. As we can see in the examples of (52) and (45) the hotel evaluates itself in an interpersonal way by using the positive reaction of quality lexically, e.g., Contemporary tropical experience, luxurious, expansive, peace, comfort, grandeur, gorgeous and lush tropical garden. They show the reader that the hotel has tropically situated, equipped and well furnished. Meanwhile, the hotel evaluates the room in the same way such as our guest room, a post-modern, contemporary style with soothing earth tones and wood interiors, for example in the clause (18) and (19): All rooms feature television and a day bed and in the clause (69): Every room features marble bathrooms. They describe the typical room in Indonesian as a tropical and multi-cultural country. It provides back to nature room, but outstanding in services. It can be seen in marble bathrooms, wood interiors, a day bed, an outstanding range of cuisine, and on-call butler service. The term oncall butler service shows availability of highest level of five starred hotel services in this hotel.

\section{Positive Reaction of Impact}

Figure 4.2 shows the result of a positive reaction of impact which reaches $11 \%$. The text is using the positive reaction of impact to attract the reader's feeling to things emotionally. It implies that the way hotel persuades the reader through arousing the feeling of positive reader's emotions. The $11 \%$ of narration of the text use that method. They are explained below:

(13) Swiss-Belresort Watu Jimbar features an amazing free-shaped

(17) Most rooms overlook our wonderful lagoon

(51) For business, the Meliá Purosani features impressive venues 
(50) The Meliá Purosani is a cozy hotel that is conveniently nestled in the center of Yogyakarta.

(56) In addition to an outdoor pool, it has a fitness center and pampering and relax,

(23) For the ultimate in relaxation, our guests

(45) Sheraton Mustika Yogyakarta Resort and spa is suitable for family vacation or romantic gateway in tropical splendor

The result shows that the positive reaction of impact tends to be used to highlight the features of hotel product in detail. It is used to arise the reader's same positive feeling if the readers stay at the hotel.

\section{Positive Reaction of Composition Balance}

It related to the writer's perception and order. It tends to answer the question "Did it hang together?" The examples are:

(22) Our international restaurant offers a menu featuring Asian and Indonesian cuisines with seasonal dishes to suit every taste, mornings, and bar offer a selection of snacks, cocktails, noon and night, and the lobby lounge and bar offer a selection of snacks, cocktails (and mocktails) throughout the day

(35) Throughout, the resort's seven themed buildings are resound with the spirit of Bali and inspired by the unique Penglipuran village, each with its own characteristic that distinguished by impressive Indonesian stonework.

(41) Along with its deluxe suites and rooms, Hyatt Regency Yogyakarta hotel also offers a multi level swimming pool, golf course, tennis courts, spa, and fitness

The examples imply the description of the combining facilities and services such as dining types, the unique hotel view, hotel facilities experience. The hotel offers the experience of tasting Indonesian culinary in clause (22), and to gain experience of Balinese customs spiritually and tradition (35). However, the hotel offers modern design in clause (41).

\section{Positive Composistion Complexity}

The result of the composition complexity is in $35 \%$. This kind of appreciation attitudinal tends to answer the question of "Was it hard to follow?". The example clauses below imply the meaning of composition complexity.

(38) Hyatt Regency Yogyakarta is a 5 star hotel in Yogyakarta, the cultural heart of Java

(54) In the heartland of Javanese culture, the Meliá Purosani marks the pinnacle of hospitality.

(6) The luxurious villa resort is located at Banjar Bindu, southwest from the heart of Ubud where the scenic drive along .... 
(15) Located in the heart of Sanur, everything is nice and close.

The interpersonal meaning of composition complexity founded in this research implies centralization in the feature of hotel location. They stated in the word such as heart of Java and the heartland of. So it could not hard to follow the hotel location if it is located in the heart of the city.

\section{Positive Reaction of Valuation}

The reaction of valuation is to evaluate the value and the worth of the hotel. It The result is $35 \%$, which means that the reaction of valuation dominated the appreciation framework in this research. The examples are:

(3) Simply created for you to completely sit back and relax, Aradhana Villas located steps away to Berawa Beach, close to a world-renowned haven for all the surfers "Echo Beach" and mere minutes from Seminyak, the most sought-after destination on the island to dine, shop and party.

(8) Whether you select our Lagoon Pool Villa or our Spa Pool Villa, be ready for a placid experience in Ubud, Bali's major artistic and cultural centre.

(71) Club-level rooms and suites have exclusive access to M Club perks like free snacks, beverages and hors d'oeuvres, while suites also offer generous living areas.

(75) The hotel is near the shops, artists and restaurants of Jalan Malioboro, Depok and

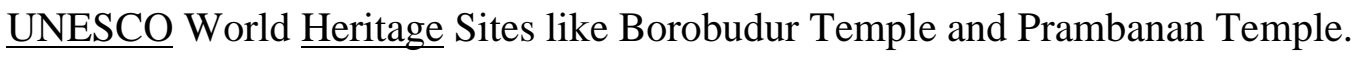

(53) For a relaxing experience, the exclusive Yhi Wellness spa delivers a full rejuvenation experience with the expert hands of our professionally trained therapists and Java's famed herbal treatments

The word and noun phrase as Java's famed herbal, expert renowned haven, most sought, major artistic, M Club perks and UNESCO World Heritage are the reaction of valuation resources. They are used to enhance the credential and credibility of the hotel from the society. It important in order to convince the guest has felt confident and secure to stay in a hotel.

\section{Judgement}

Figure 4.1 indicates that the Indonesian ten hotels give more focus on promoting the quality of facilities and services rather than showing the hospitality of the staff hotel. It is because judgment is related to people behavior. These evaluations are implied in the clauses below:

(49)... our professional team is happy to accommodate you in our stunning_Grand Ballroom

(53) ... experience with the expert hands of our professionally trained therapists our and Java's famed herbal treatments 
The results show the positive judgment of staff hotel behavior. The adjective of professional, happy and verb of accommodating can be classified in the judgment of esteem capability. They imply the capability and professionality of their staff hotel teamwork in offering happiness and caring service to make sure the guest would be taken care while hosting the wedding or social gathering. The professionality related to the capability of staff hotel in giving the customized appreciation dinner while the guest host the social gathering in the hotel. While the behavior of happiness will be delivered in serving the guest. The same prosody is delivered on clause 53 .

\section{Affect}

The evaluative language of affective implies to how people feel. Figure 4.1 indicates that the hotel more focuses on offering the facilities and service rather than arising the guest's feeling toward the hotel. The implication of these is explained by the examples below:

\section{(25) WELCOME TO FAIRMONT SANUR BEACH BALI}

(23) For the ultimate in relaxation, our guests enjoy a cooling dip in the glorious pool or a refreshing spa and massage treatment to rejuvenate body and mind.

(45) Sheraton Mustika Yogyakarta Resort and SPA is suitable for a family_vacation or romantic gateway in tropical ...

(72) Work out in the 24-hour gym, take a dip in the indoor/outdoor connecting pool or pamper yourself in the spa.

(67) Whether you are visiting Yogyakarta, Indonesia for business or leisure, Yogyakarta Marriott Hotel welcomes you with superb service, spacious rooms and 5-star amenities.

The result of the data analysis shows the use of positive verb in clause (25) and (67). They evaluate the word welcome, which means to welcome guest while they are entering the hotel physically. It indicates the attentive service and the caring offered by the hotel in establish a positive relationship with the potential guest. The examples in clause (72) and (23) imply the feeling of indulging with every attention, comfort, enjoyment and refreshment offered to the guest during treatment in Spa. It arouses the guest feeling of comfort and spoiled. The hotel evaluates the word romantic (45) which means the hotel offers the romantic situation such as for lovers to stroll hand-in-hand.

\section{Graduation}

It construes the greater or lesser the positivity or negativity of attitudinal meaning. These meaning will be explained in the sub-discussion suitable with the type of graduation.

\section{Intensification: Quality Maximisation}

The hotel uses the intensification: quality to weight the product and services that the hotel 
offers. The resource of pre and post modification of adjective and nominalized quality will intensify the further weight of hotel product and hotel services. The intensification: quality maximization tends to shows that the hotel is not only good but also superior in their identity. The examples of quality maximition resources are:

(2) All villas come with private swimming pool, ...

(41) ...Yogyakarta hotel also offers a multi level swimming pool,

(51) The hotel stands a short distance from the airport and is moments from many popular attractions, including the souvenir paradise of Malioboro shopping district, the ancient Hindu relics of Prambanan Temples, and the Sultan's Palace.

(52) ... an outstanding range of cuisine,

(53) For a relaxing experience, the exclusive Yhi Wellness spa delivers a full rejuvenation experience with the expert hands of our professionally trained therapists and $\underline{\text { Java's }}$ famed herbal treatments

(54)... make it ideal for hosting first-class meetings and events

(55) In the heartland of Javanese culture, the Meliá Purosani marks the pinnacle of hospitality

The lexical of private (2), a multi-level (41), outstanding (52), exclusive (53), our professionally trained therapists_(53), Java's famed (53) and first class meeting (54) show that the hotels provide the higher grading of hotel facilities. The interpersonal meaning of the hotels is good in serving the guest better than the others are shown in the example clauses (54) in the words of first class, ideal for hosting and the pinnacle of hospitality (55). Especially in doing treatment for the guest, the Yhi Wellness Spa is better than other (53). While clause 51convinces the reader that the hotel location is the closer to the worth others tourism accommodation and destination.

\section{Intensification: Quality Superlative}

Intensification: quality superlative construes the interpersonal meaning of " I am the best", there is no comparative thing. The hotel evaluates its product using the intensification: quality superlative in order to persuade and ensure the reader to stay in the best hotel service, the best hotel facilities and the best hospitality in the world. The intensification: quality superlative resources work in the examples below:

(1) ... designed to make the most out of each stay

(2 ) ...unique Balinese inspired artistry and most everything you could possibly imagine from a luxury boutique pool villa experience 
(3 ) ...from Seminyak, the most sought-after destination on the island to dine, shop and party.

(31)...Fairmont Sanur Beach Bali promises to be the best that Bali has to offer, and a haven for guests to revitalize and rejuvenate

(74) Meeting planners appreciate the sophisticated venues, including Yogyakarta's largest ballroom

(75) The hotel is near the shops, artists and restaurants of Jalan Malioboro, Depok and UNESCO World Heritage Sites like Borobudur Temple and Prambanan Temple.

The interpersonal of I am the best in providing hotel facilities could be seen from the example clause (74): the largest ballroom, and (2): the best swimming pool. The hotel evaluates the view hotel in the meaning of I am the best hotel view in the world, it could be seen from (1) the most out, (3) the most sought, and (31) the best hotel that Bali has to offer, Especially, no (75) the lexical of World Heritage Sites describes that the hotel location is not too far from the most important heritage site in the world.

\section{Intensification: Metaphor}

Intensification: metaphor related to the figurative language used in the hotel text. The interpersonal meaning of this evaluative resources is not to forget the image idea of the hotel, because the function of figurative language is to build the mental process of hotel identity with words. The examples are:

(29) ..., peace and round-the-clock on-call butler

(14) ...it's all just a stone's throw away from magnificent Swiss Belresort

(15) If you're looking for a little retail therapy, or want to let your hair down in the evenings, there is an abundance of shopping and nightlife options right at your doorstep.

The lexical of round-the-clock (29) implies that the hotel offers twenty-four hours service to the guest. Clause (14) exaggerates the distance nearest of hotel location to the beach,while clause (15) shows that the hotel location is near to the other local leisure place. The interpersonal meaning of evaluative figurative language in the persuasive text is to memorize brand image of the identity of the hotel. Under the circumstance of politeness the opinion may deliver in figurative language.

\section{Intensification: Quality Comparative}

The used of intensification: quality comparative is the same meaning with the intensification: quality superlative and intensification: maximisation. In the example clause (4) the evaluative 
language of the word easier shows that the hotel provide better accommodation especially transportation than others.

(4) Our complimentary transportation services make it even easier.

\section{Intensification: Process Attitudinally}

The intensification process attitudinally is used to intense the process of increasing vigor by infusing the word even it is using pre-modification.

(39) The hotel is situated in the scenic outskirts of north-western Yogyakarta, elegantly set in 22 hectares of beautifully landscaped hotel garden

(51) The hotel stands a short distance from the airport and is moments from many popular attractions, including the souvenir paradise of Malioboro shopping district, the ancient Hindu relics of Prambanan Temples, and the Sultan's Palace.

The examples in clause (39) "coloring by a pre and post-modifier noun to greater intensity the process of situated of the hotel garden" and (51) "the process of a stand" explore the infusion manner that invokes increased vigor. The description of situation of hotel is intensified by post modifier scenic outskirts. It implies the green, fresh and tranquility. The manner of elegantly and beautifully strengthened the environment of the hotel as a landscaped hotel garden. The same prosody is in the example clause (51). The process of stand implies the location of the hotel near the beach. The post modifier: short distance to the airport, the most popular attraction, ancient Hindu relic and Sultan's Palace are the extensions of near location to that hotel.

\section{Quantification of Experiential meaning}

Quantification of experiential meaning related to how do experiential meanings are intensified by quantification. This quantification is used to intensify the extent of the hotel product offered in order to claim that hotel facility and hotel service are more credible and trustworthy to the reader. For example:

(29) ...the 120 luxurious suites and villas,

(45) .... in tropical splendor, we serve $\underline{3 \text { pools }}, \underline{1 \text { main restaurant, } 1 \text { India's Restaurant, }}$

(39) ...elegantly set in $\underline{22 \text { hectares }}$ of beautifully landscaped hotel gardens

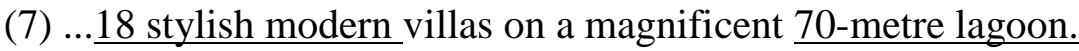

The examples of (29) and (45) show the quantification number used to invoke attitude. The quantification number of 120 belong to a positive evaluation of the co-text luxurious (29) and the figure of 3 pools, 1 main restaurant, 1 India's Restaurant, intensify the appreciation of splendor. 18 stylish figure (7) has a positive evaluation of appreciation quality of modern. 
The listing number of hotel facilities is shown in all the clauses construes the amplification of positive value quality on the hotel homepage. So it explains the interpersonal meaning of the hotel is credible and trustworthy.

\section{Graduation of Focus}

There are two terms to explore the graduation of focus, the valuer of authenticity and valuer of specificity. They imply the authentic It has the function of amplifying in grading authentic and specific of a hotel in distinguishing the hotel product from others, that it could offer to the guest.

(30) ...which specializes in authentic Indonesian cuisine; Nyala Beach

(33) Nevertheless, your holidays are made of memories and experience an authentically Balinese-modern luxury resort, nestled right in front of the Indian Ocean.

The valuer of specificity resources implies the specializes Indonesian cuisine, in the example (30) and the authenticity of modern Balinese custome in the example (33). The hotel employs force of maximization and appreciation of authentic to intensify the quality. The hotel claims a high degree prototypicality of Indonesian cuisine (30) and offers prototypicality of Balinese culture for the guest.

\section{Engagement}

The expression of completely and renowned in the example (3) can be classified into proclaim through concur. It has function to affirm the quality that the hotel is tranquil and famous for surfers to stay in. Similar to the clause 42, the proposition the word enjoy implies to entertain the guest through the availability of the Camp Hyatt programme for kids as a hotel facility. For both hotel, the proposition serves as warrant so they can engage the guest positively to hotel.

(3)....you to completely sit back and relax, ARADHANA VILLAS located steps away to Berawa Beach, close to world renowned haven for all the surfers “

(42) Kids will enjoy the Camp Hyatt programme.

The pronouncing of the example (31) implies that the hotel proclaims its promise to give the best services. The hotel proclaims that the wonderful facilities and services await the customer. It is as engage positively to that hotel. The expression getting you straight into holiday mode. It implies the alligment to the reader.

(31) Fairmont Sanur Bali promises to be the best that Bali has to offer, 


\section{Vision Mission of the hotels}

Vision and mission of the hotels mean their identity. Most of hotels vision is attempting to become the best provider for the comfortable hospitality industry by introducing the unique Indonesian culture as a tropical country and offering hospitality with international standards. Meanwhile, most of the hotel mission is attempting to deliver truly memorable experiences for the customers to taste Indonesian culture and serving them with the innovative product in international standard. All then imply that the result of this research that the interpersonal meaning of the ten hotels in Indonesia "I want it" is in line with the vision-mission of the ten hotels that always upgrade their facilities and services to attract the customer to stay in.

\section{CONCLUSION}

The result of this research shows that $44 \%$ are dominant on the appreciation of quality. It implies that the interpersonal meaning of many Indonesian hotels focused on promoting the quality of facilities and services. Besides, the hotel vision missions stated that they always upgrade their hotel products. It has an impact to arouse the desire of the customer to have a feeling of "I want it". The word "it" could be replaced by an object (object or things) in detail. The examples are (1) I want to stay in Javanese style rooms and Suite rooms, each with magnificent balcony and surrounded by a tropical garden, (2) I want to taste Indonesian culture of living etc. The detail explanation of things in the text could align the reader which means in order to persuade the reader to purchase hotel products.

The comparative research in the appraisal at an Indonesian hotel will be recommended for the next research. It will compare the result of this research with the next research to know the upgrading product of the hotel in promoting through their webpages.

\section{REFERENCES}

Bhatia, K. V. (2013). Analysing genre: Language use in professional settings. USA Routledge.

Geoff T., Laura A.J. (2014). Evaluation in context. Retrieved on February, $12^{\text {th }} 2018$ .From https://books.google.co.id/

Halliday, M.A.K. 1994. An Introduction to Functional Grammar : Second Edition. London. Edward Arnold.

Martin, J. R \& White. (2005). the language of evaluation: appraisal in english. Palgrave. Britain.

Hunston, S. \& Thompson, G. (eds). (2001). Evaluation in text: Authorial stance and the construction of discourse. Oxford: Oxford University Press. 
Suyik Binarkaheni

Yi, Soen On. (2013). Hotel websites as corporate communication. Hongkong Polytechnic University Department of English. 